Canadian

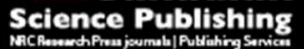

Canadian Journal of Civil Engineering Revue canadienne de génie civil

\title{
Impact of Using Indirect Left-turns on Signalized Intersections' Performance
}

\begin{tabular}{|r|l|}
\hline Journal: & Canadian Journal of Civil Engineering \\
\hline Manuscript ID & cjce-2016-0259.R2 \\
\hline Manuscript Type: & Article \\
\hline Date Submitted by the Author: & 29-Jan-2017 \\
\hline Complete List of Authors: & $\begin{array}{l}\text { Taha, Mahmoud; American University of Sharjah, Civil Engineering } \\
\text { Abdelfatah, Akmal; American University of Sharjah, Civil Engineering }\end{array}$ \\
\hline $\begin{array}{r}\text { Please Select from this Special } \\
\text { Issues list if applicable: }\end{array}$ & \\
\hline Keyword: & Traffic signal optimization, Indirect left-turns, Microscopic simulation \\
\hline & \multicolumn{2}{|c|}{} \\
\hline
\end{tabular}

SCHOLARONE ${ }^{m}$

Manuscripts 


\title{
IMPACT OF USING INDIRECT LEFT-TURNS ON SIGNALIZED INTERSECTIONS' PERFORMANCE
}

Mahmoud Taha, Akmal Abdelfatah

\section{Mahmoud Taha}

American University of Sharjah

Sharjah, United Arab Emirates

Tel: + (971) 50639 6282; Email: Taha.MahmoudAhmed@gmail.com

\author{
Akmal Abdelfatah \\ American University of Sharjah \\ Sharjah, United Arab Emirates \\ Tel: + (971) 65152903 Fax: + (971) 6515 2979; Email: akmal@aus.edu
}


Abstract: The majority of traffic delays in urban areas occur at signalized intersections. Due to the limited availability of space and right-of-way, many transportation agencies are considering unconventional traffic control systems for intersections to improve signal efficiency and reduce overall delays. Common unconventional left-turn treatments include the right-turn followed by a U-turn (RTUT) and a U-turn followed by a right-turn (UTRT). The main goal of this study is to determine the traffic operational performance of the three left-turn treatments under different traffic conditions. The results showed that unconventional left-turn control types have less delay and travel time compared to the direct left-turn (DLT), when the U-turn locations are 200 meters away from the main intersection. Also, RTUT showed superior performance over the other left-turn control types, when the U-turn locations are 100 meters away from the main intersection.

Keywords: Traffic signal optimization, indirect left-turns, microscopic simulation 


\section{Introduction}

In most urban areas, traffic growth means higher delays at signalized intersections. As a solution to reduce traffic delays, oftentimes agencies add more lanes to reduce the delay. However, such solutions are not always feasible for many intersections due to the limited right-of-way. Using unconventional left-turn control types is one of the possible solutions to reduce the overall delay and improve signal efficiency with minimal changes to the existing geometric design. The main purpose of unconventional left-turn treatments is eliminate direct left-turns (DLTs) and to reroute left-turning vehicles away from the main intersection.

There are many alternatives to eliminate direct left-turns at signalized intersections. The signalized intersection will be controlled by a two-phase traffic signal, after eliminating DLTs. A right-turn followed by a U-turn (RTUT), and a U-turn followed by a right-turn (UTRT) are possible left-turn treatments. For the RTUT control type, vehicles desiring to turn left must first turn right at the main intersection through a signalized right-turn lane. After that, vehicles must make a U-turn at a signalized median opening downstream of the intersection, and then travel through the main intersection, as illustrated in Figure 1a. For the UTRT control type, vehicles desiring the turn left must first travel through the signalized intersection. After that, vehicles must make a U-turn at a signalized median opening, and then make a right-turn at the main intersection, as illustrated in Figure $\mathbf{1 b}$.

Unconventional left-turn treatments aim to reduce conflicts and enhance safety along arterial roads; at the same time, they have minimum impact on the existing geometric design. Unconventional left-turn treatments could be implemented with traffic signals at the U-turn locations.

This study evaluates the operational performance of three left-turn control types under different traffic conditions. Also, the study illustrates the impact of changing different traffic parameters on each left-turn treatments. Therefore, the study provides recommendations about the left-turn control type to be used based on the prevailing traffic conditions. 


\section{Literature review}

Several research efforts (Gluck et al. 1999; Zhou et al. 2000; Zhou et al. 2001; Gue et al. 2011a; Gue et al. 2011b) have considered the operational impact of replacing direct left-turns with U-turns. Levinson et al. (2000) provided an overview of the indirect left-turn control type that has been implemented in Oakland County, Michigan (Michigan "U”). Their study discussed the design features of this new concept, and also compared the capacity and level of service of the Michigan "U" with the conventional left-turn control type. Finally, the paper discussed operational and safety effects of the Michigan " $U$ " control type.

Many transportation agencies have started using unconventional left-turn treatments as alternatives to direct left-turns from driveways. For instance, the Florida Department of Transportation (FDOT) prohibits direct left-turn (DLT) from driveways in many locations. As a result, drivers desiring to turn left have to make RTUT at a downstream U-turn location rather than making a direct left-turn onto a major-street from driveways. At un-signalized intersections, the main purpose of using a right-turn followed by a U-turn is to reduce conflict points associated with the direct left-turns (Zhou et al. 2002). Recently, Al-Omari and Al-Akhras (2014) developed some delay models for median U-turns (MUT) on multilane highways. The models were based on collected data from Jordan. The delay models were developed for MUT considering different levels of turning and conflicting traffic volumes.

\section{Traffic Operational Performance}

Hummer and Reid (1999) compared a right-turn followed by a U-turn with the conventional direct left-turn for signalized intersections. In their study, they investigated the impact of utilizing U-turns on an arterial median only. After conducting the analysis, it was recommended that transportation agencies should consider this alternative when high through volumes conflict with moderate or low left-turn volumes.

Traffic signals will be operating with two phases only after prohibiting left-turns at signalized intersections. Reducing the number of phases has many advantages, such as 
increasing the capacity of the intersection and improving the level of service. In some cases, traffic signals at the U-turn locations are slightly delayed based on the separation distance between the intersection and the U-turn locations. Cycle length varies between 60 and 120 seconds in most cases studied (Bared and Zhang 2007). Another study found that prohibiting direct left-turns at signalized intersections and providing two-phase signal controls improved the intersection capacity by about 20 to 50 percent (Maki 1996). In a more recent study, (Zhou and Zhang 2014) considered an intersection where indirect left-turns are considered on two of the intersection approaches. They developed a mixed linear program to optimize of the main traffic signal and the two signals at the U-turn locatons that can improve the efficicency of the intersction.

Gyawali (2014); Gyawali et al. (2015a, 2015b) developed some decision support curves to determine the need for an indirect left-turn at a signalized intersection. The analysis considered intersections with one major road and one minor road. It also sonsidered left turn percentages of $5 \%$ to $15 \%$ on the major road with small traffic volumes on the minor road. The three studies concluded that the indirect left-turn showed better performance than direct left-turns in all scenarios. In addition, Lin et al. (2015) developed delay models for direct left turn and one indirect left turn (right turn followed by U-turn). They concluded the the left turn volume has to reach some threshold in order for the indirect left turn to outperform the direct left turn. However, this study considered the intersection delay rather than the overall travel time.

Several studies investigated the operational effects of unconventional left-turn treatments using simulation packages such as Synchro, SimTraffic, and CORSIM. The primary goal of using simulation techniques is to help researchers recognize the impact of changing different parameters within the study. Also, using such analytical tools can help in simulating as many scenarios as needed to reach precise conclusions. Using simulation packages are very useful and efficient for any parametric study. 
Another study evaluated the operational performances of DLTs and RTUTs from driveways, under different traffic conditions. Delay and travel time were considered in order to evaluate each alternative, and CORSIM software was used as the analytical tool. The simulation results showed that a DLT has better performance at low through-traffic volume on a main street. However, the RTUT control type shows less delay and travel time under moderate to high volumes on main streets. The study can be used as a guidance to determine which left-turn control type is more effective under the given traffic conditions (Yang and Zhou 2004).

Reid and Hummer (1999) investigated the operational performance of using median U-turns as alternatives to two-way left-turn lanes (TWLTLs). The U-turns were provided on the major arterial only, and all major driveways and unsignalized side streets intersecting with the corridor were considered in the study. Based on the results, median U-turns showed a 25 percent increase in the average speed, and a 17 percent decrease in the total travel time as compared to TWLTLs. However, median U-turns showed a higher number of stops compared to TWLTLs.

A study used CORSIM software to evaluate the impact of using signalized U-turns on typical 4-leg intersections formed by two 4-lane roads intersecting with each other. The U-turns were provided only on both sides of the major road, and left-turning vehicles from the minor road were allowed to turn at the main intersection. The study considered a three-phase signal operation with a direct left-turn movement from the cross-street. The results indicated that a significant reduction in travel time could be achieved for the signalized U-turn design at high traffic volumes (Bared and Kaisar 2002).

Dorothy et al. (1997) used the TRAF-NETSIM model to simulate the impact of using RTUTs compared to two-way left-turn lanes (TWLTL). The U-turn locations were modeled as STOP-controlled with low turning volumes, and signalized U-turns were assumed to have higher turning volumes. For left-turning volume of 10 and 25 percent, the RTUT control type 
had lower network travel times compared to conventional intersections. Moreover, the STOP-controlled and the signalized U-turns had the same left-turn total time under low left-turning volumes.

Another study considered unconventional left-turn control types at signalized intersections, where a major road and a minor crossroad intersected with each other, and direct left-turns were prohibited at the intersection. For most of the volume combinations, the U-turns located on the crossroad reduced the total travel time, delay, and the number of stops in comparison to the U-turns on the major road (Topp and Hummer 2005).

CORSIM software was used in a study to compare the direct left-turn (DLT) with two forms of unconventional left-turn control types including a right-turn followed by a U-turn (RTUT), and a U-turn followed by a right-turn (UTRT). The study considered an intersection of a major road with a minor road. Total travel time, speed average, and speed variance were used as the measures of effectiveness (MOE) in evaluating the operational performance of the three left-turn control types. Based on the simulation results, unconventional left-turn control types were more effective than direct left-turns (Lu et al. 2012).

Another study examined the impacts of using U-turns on level of service of signalized intersections, and Synchro and SimTraffic were used as the analytical tools. The results of the regression model showed that the impact of U-turns on the level of service of signalized intersections needs to be evaluated on a case-by-case basis (Changjiang et al. 2009).

\section{Safety Performance}

To improve the performance of unconventional left-turn control types, the location of the U-turns has to be selected wisely. In fact, large separation distance may discourage drivers from making indirect left-turns because they will experience longer travel time due to the additional distance travelled. On the other hand, short separation distances will cause safety problems at the weaving sections of the road, and vehicles making RTUTs will not have 
sufficient distance to complete the lane change maneuver in a comfortable way (Ronglong et al. 2010).

Various research efforts (Xu 2001; Kach 1992; Potts et al. 2004; Lu et al. 2001; Lu et al. 2004; Lu et al. 2005; Lu et al. 2001) have evaluated the safety effects of using U-turns as alternatives to direct left turns. The results indicated that using U-turns reduced the number of conflict points and crashes compared to direct left-turns. The number of merge/diverge conflict points is reduced from 16 points to 12 points, when using median U-turns, as compared to a four-leg signalized intersection. Moreover, all crossing (left-turn) conflict points were eliminated in the case of median U-turns.

Liu et al. (2007) compared the safety performance of different left-turn control types including a DLT, RTUT at a median opening, and a RTUT at a signalized intersection. Unconventional left-turn movements generate fewer conflicts compared to direct left-turn movements. Also, vehicles making RTUTs at a median opening generate fewer conflicts than those making RTUTs at a signalized intersection.

In another study, seventy eight sites were selected to investigate the safety performance of U-turns at signalized intersections. During the 3-year study period, 65 of the 78 sites did not have any collisions involving U-turns. For the remaining sites, U-turn collisions ranged from 0.33 to 3.0 collisions per year (Carter et al. 2005).

Based on the literature review conducted, unconventional left-turn treatments may reduce delays, travel time, and conflicts as compared to the direct left-turn control type at driveways and signalized intersections. Also, reducing the number of phases improves the capacity and the level of service of the intersection.

As it is noticed from the previous studies, there are solid evidences that using U-turn treatments as alternatives to direct left-turns from driveways reduces the delay and the travel time under moderate and high traffic volume conditions. This study investigates if the same advantages could be achieved by eliminating DLTs at signalized intersections instead of 
driveways. In addition, some studies considered providing U-turns at signalized intersections either on the major road or on the minor road. However, this study investigates the operational effects of using U-turns on both arterials. Furthermore, the traffic volume was assumed to be dominant on the major road in the previous studies. However, in this study, traffic volume is distributed to cover more cases (i.e. equally distributed on all approaches, dominant on two opposite approaches, and dominant on two perpendicular approaches). Some of the previous studies considered the impact of left-turning percentages, ranging from 10 to 25 percent, on the intersection's performance. However, in this study the left-turning flow is ranging from 15 percent to 45 percent.

\section{Methodology}

This study considers an intersection of two major roads that may serve comparable traffic volumes. In this study, the analysis was performed to demonstrate the impact of using a combination of right-turns and U-turns, as alternatives to direct left-turns, on the intersection's performance. Also, to determine the most efficient left-turn control type for each scenario based on the prevailing traffic conditions. Finally, to recommend the optimal U-turn locations for unconventional left-turn control types, for all of the considered scenarios.

Certain procedures were followed to investigate the operational effects of using unconventional left-turn control types as alternatives to direct left-turns at signalized intersections. Three microsimulation models were developed, using Vissim, to investigate three left-turn control types: direct left-turns (DLT), right-turns followed by U-turns (RTUT), and U-turns followed by right-turns (UTRT). Many scenarios were considered through the variation of some traffic parameters to examine each left-turn control type. For the analysis, Synchro software was used to determine the optimized signal timing and the delay at the signalized intersection for each scenario. The optimized signal timings were then applied within Vissim software to evaluate the overall performance of each intersection. 


\section{Geometric Characteristics and Signal Timing}

Figure 2 illustrates the layout for the RTUT and UTRT left-turn control types. The dimensions are fixed at a constant value among the three left-turn control types so that an unbiased comparison can be made among the control types.

For the right-turn followed by a U-turn control type, drivers desiring to turn left must first turn right at the main intersection through a signalized right-turn lane. After that, drivers must make a U-turn at a signalized median opening downstream of the intersection. For vehicles that are originally turning right on the intersection, the free right-turn canalizations are separated from the other lanes to allow right-turning vehicles to move without stopping at the signal. The separation is extended beyond the location of the U-turn to prevent right-turners from taking the U-turn at the median opening.

For U-turns followed by right-turns control type, drivers desiring to turn left must first pass through the signalized intersection, make a U-turn at the signalized median opening, and then make a right-turn at the main intersection. In this control type, the right-turn channelization is shared between vehicles desiring to turn right and vehicles coming from the U-turn (desiring to perform indirect left-turns).

The phasing diagram consists of four phases for DLT control type. Split signal phasing was used for this left-turn control type, which gives the green time for all vehicle movements of one direction followed by a phase for all vehicle movements of the opposite direction. The phase diagrams for unconventional left-turn control types consist of only two phases, as shown

\section{in Figure 3.}

\section{Considered Parameters}

As shown in the experimental design, presented in Figure 4, different parameters were considered in the analysis including the total volume on the intersection, the left-turn control type, the traffic volume distribution on each approach, the percentage of vehicles for each turning movement, and the location of the U-turns. The values for the total traffic volume on 
the intersection were selected to represent low, moderate, high, and very high traffic volumes. It should be noted that Figure 4 illustrates the experimental design for one traffic volume only. The same parameters apply for the other traffic volumes as well. The analysis included 420 scenarios, which is a reasonable number to reach precise conclusions.

Three left-turn control types were considered in the analysis, and English alphabets were used to identify each case. Case (a) represents DLT control type, whereas cases (b) and (c) represent RTUT and UTRT, respectively.

The traffic volume distribution on each approach represents several cases, and Arabic numbers were used to identify each case. For case 1, the total traffic volume is equally distributed on all approaches of the intersection, which represents a case where all of the approaches have the same level of congestion. For cases 2 and 3, traffic volume is dominant on two opposite approaches. Furthermore, for cases 4 and 5, traffic volume is dominant on two perpendicular approaches.

The percentage of vehicles for each turning movement represents three cases, and roman numerals were used to identify each case (i.e. I, II, and III). For all cases, right-turn movements represent $10 \%$ of the total volume assigned to each approach, and the turning percentages for the eastbound and the westbound approaches are constant. For case I, the left-turn movements for the northbound and the southbound approaches represent only $15 \%$ of the total volume assigned to these approaches. Moreover, the left-turn percentage represents $30 \%$ for case II and $45 \%$ for case III of the total volume assigned on the northbound and the southbound approaches.

\section{Results and Discussion}

The analysis was performed to evaluate three left-turn treatments: DLT, RTUT, and UTRT. Synchro software was used to determine the optimized signal timing at the main intersection and at the signalized U-turn locations, and the Vissim software was used to evaluate the intersection's overall performance. 
Because calculating delay for unconventional left-turn control types using Synchro is misrepresentative, more detailed analysis was performed using Vissim software. A model for each left-turn control type was created using Vissim to evaluate the overall delay for different scenarios. All scenarios presented in the experimental design were simulated using Vissim, and network performance was obtained for each scenario.

To achieve robust results, five runs were performed and the trimmed mean was calculated by excluding the largest and the smallest values from the results, and calculating the arithmetic mean of the remaining three values. The trimmed average was used in this study to reduce the effects of random variations on the calculated mean.

\section{Delay comparison.}

Table 1 presents overall delay (obtained from Vissim simulations) comparisons for the three left-turn control types, where the U-turn locations are 200 meters away from the main intersection. Also, the left-turn movements for northbound and southbound approaches are equal to $15 \%, 30 \%$, and $45 \%$.

For case 200.I.1, DLT control type shows more delay compared to the unconventional left-turn treatments, as shown in Figure 5. At low traffic volumes, intersection delay is very similar between DLT and RTUT control types; however, the gap between the two curves increases as the traffic volume increases. The UTRT control type has the least delay among all of the left-turn control types, irrespective of different traffic volumes. In these simulations, the U-turn locations are 200 meters away from the main intersection; accordingly, vehicles making indirect left-turns take a considerable amount of time before reaching the U-turn locations. In the case of a RTUT, the traffic light at the U-turn changes from green to red before vehicles reach the U-turn locations. Therefore, vehicles making RTUTs stop at the signalized intersection and the U-turn location, whereas vehicles making UTRTs stop only once at the signalized intersection. 
Table 2 presents delay comparisons for the three left-turn control types, where the U-turn locations are 100 meters away from the main intersection. Also, the left-turn movements for northbound and southbound approaches are equal to $15 \%, 30 \%$, and $45 \%$.

As illustrated, the delay for unconventional left-turn control types is less compared to a DLT when traffic volume is equally distributed on all approaches or dominant on two opposite approaches (i.e. cases 100.I.1, 100.I.2, and 100.I.3) over the considered range of traffic volumes. When the traffic volume is dominant on two perpendicular approaches (i.e. cases 100.I.4 and 100.I.5), the delay for the UTRT increases significantly as the traffic volume exceeds 6,000 vph. This can be attributed to the queue spillback effect when moving the U-turn locations closer to the intersection. Furthermore, the delay for the unconventional left-turn control types is comparable at low traffic volumes since there are no long queues at the signalized U-turn locations. For case 100.I, it seems that a right-turn followed by a U-turn has superior performance compared to the other left-turn control type over the considered range of traffic volumes.

Table 3 presents delay comparisons for the three left-turn control types, where the U-turn locations are 50 meters away from the main intersection. Also, the left-turn movements for northbound and southbound approaches are equal to $15 \%, 30 \%$, and $45 \%$.

As illustrated, unconventional left-turn control types have comparable delay at traffic volumes less than 5,000 vph. At high traffic volumes, the delay for UTRTs reach to extremely high values compared to the other control types. Also, intersection delay for the RTUT control type increases at a higher rate when traffic volumes exceed 6,000 vph. In fact, moving the U-turns closer to the intersection causes safety problems at the weaving sections of the road for unconventional left-turn control types. Also, vehicles making RTUTs will not have sufficient distance to complete the lane change maneuver in a comfortable way; therefore, the intersection will be blocked as a result of the spillback effect. For case 50.I, the direct left-turn 
has superior performance compared to the unconventional left-turn control types at high traffic volumes.

\section{Travel time comparison}

The values for the average travel time were compared among the three left-turn control types for all of the considered scenarios. It should be noted that the travel time curves follow the same trend as the delay curves for the same reasons mentioned earlier in the delay comparison.

\section{Vehicle kilometers travelled comparison}

A comparison based on the vehicle kilometers travelled (VKT) was made among the three left-turn control types for each case. VKT is the total distance in kilometers travelled by all vehicles during a given period of time on a particular road system. Figure 6 illustrates the VKT comparisons for case 200.I.1. The direct left-turn control type has the least VKT compared to unconventional control types. There is no significant difference (less than $8 \%$ ) in distance travelled between direct left-turn and unconventional left-turn treatments. Moreover, RTUT and UTRT control types have approximately the same vehicle kilometers travel (VKT).

All the other cases have a similar trend as case 200.I.1.

\section{Level of service comparison}

Level of Service (LOS) comparison was made to evaluate capacity and operating conditions for the three left-turn control types. Level of service is a function of the average control delay. There are many factors affecting the average control delay such as signal phasing, signal cycle length, and volume to capacity ratio at the signalized intersection (Highway Capacity Manual 2000). 
Table 4Table 4 summarizes the level of service for the three left-turn control types for all of the considered U-turn locations. As illustrated, similar cases were combined together when there was no significant difference on the level of service (i.e. only one letter difference). Combining similar cases helps to visualize the impact of each parameter on the left-turn control types.

\section{Impact of U-turn location}

The impact of a U-turn locations on the operational performance of unconventional left-turn control types was investigated under different traffic conditions. Three different U-turn locations were investigated at 200 meters, 100 meters, and 50 meters. Figure 7 illustrates the impact of changing the location of the U-turns for the RTUT control type.

Figure 7A presents case I, where left-turn movements for the northbound and the southbound approaches represent $15 \%$ of the total volume assigned on these approaches. As shown, each column presents the average delay for one of the scenarios presented in the experimental design. The dashed line presents LOS E, where the overall delay of the intersection is equal to 55 seconds. The majority of the scenarios have a comparable delay at all of the considered U-turn locations. However, the average delay increases dramatically for three scenarios (I.1.b.7000, I.4.b.7000, and I.5.b.7000) when the U-turn locations are 50 meters away from the main intersection. When the total volume on the intersection reaches $7,000 \mathrm{vph}$, the average delay increases significantly for the RTUT control type when moving the U-turns very close to the main intersection (i.e. at 50 meters).

Figure 7B presents case II, where left-turn movements for the northbound and the southbound approaches represent $30 \%$ of the total volume assigned on these approaches. As illustrated, all of the scenarios have a comparable delay when U-turn locations are at 100 and 200 meters. However, when the U-turn locations are 50 meters away from the main intersection, the average delay increases dramatically for many scenarios (II.1.b.7000, II.2.b.6000, II.2.b.7000, II.3.b.6000, II.3.b.7000, II.4.b.6000, II.4.b.7000, II.5.b.5000, 
II.5.b.6000, and II.5.b.7000). When the total traffic volume exceeds $6,000 \mathrm{vph}$, the intersection delay increases significantly for case II.b when moving the U-turns very close to the main intersection (at 50 meters).

Figure 7C presents case III, where left-turn movements for the northbound and the southbound approaches represent $45 \%$ of the total volume assigned on these approaches. As illustrated, when the U-turn locations are 100 meters away from the main junction, the intersection delay increases for many scenarios (III.1.b.7000, III.2.b.6000, III.2.b.7000, III.3.b.6000, III.3.b.7000, III.4.b.6000, III.4.b.7000, III.5.b.6000, and III.5.b.7000). The intersection delay increases significantly when the traffic volume reaches $6,000 \mathrm{vph}$, regardless of the traffic volume distribution between the approaches. In addition, the average delay increased dramatically for most scenarios when the U-turn locations were 50 meters away from the main intersection. In fact, many scenarios require more offset distance for case III.b, as shown in Figure 7C.

\section{Conclusions and recommendations}

This paper investigated the operational effects of three left-turn control types including direct left-turn (DLT), right-turn followed by a U-turn (RTUT), and a U-turn followed by a right-turn (UTRT). The study evaluated the impacts of the U-turn locations relative to the signalized intersection for each unconventional left-turn control type. The software packages Synchro and Vissim were utilized to evaluate each alternative. The conclusions of the study are summarized as follows:

1) When the U-turn locations are 200 meters from the main intersection, unconventional left-turn treatments show superior performance compared to the direct DLTs.

2) When the U-turn locations are 100 meters from the main intersection, unconventional left-turn control types show superior performance compared to the direct left-turn control type for all of the considered cases. When the left-turn percentage is less than $30 \%$, the RTUT and the UTRT show similar traffic performance over the considered 
range of traffic volumes. However, when the left-turn percentage is equal to $45 \%$, the RTUT shows superior performance compared to the other left-turn treatments.

3) When the U-turn locations are 50 meters from the main intersection, unconventional left-turn control types show superior performance when the left-turn percentage is equal to $15 \%$ under low and moderate traffic volume conditions. However, DLTs show better performance under high traffic volume conditions. When the left-turn percentage exceeds $15 \%$, DLTs show superior performance compared to the other left-turn treatments over the considered range of traffic volume.

4) Moving the U-turn locations closer to the intersection increases the average delay dramatically for unconventional left-turn treatments due to the queue formation at the U-turn locations and the spillback effect, which blocks the signalized intersection. Before implementing unconventional left-turn control types, transportation agencies and municipalities should consider the following issues:

1) Driver confusion and the impact of implementing unconventional left-turn control types on a driver's behavior. The signage on the approaches to the intersections should be very clear and noticeable to drivers. Also, public announcements should be made to indicate the change in traffic control system within the given city/area.

2) Traffic violation to the left-turn prohibition at the main intersection.

3) Enforcement and education to prevent illegal turns at the signalized intersection.

4) U-turns need to accommodate large vehicles if needed. This could be achieved by building a wider median.

Future research related to the impact of U-turns as alternatives to direct left-turns may include the following cases:

1) Different layouts of intersections (i.e. a different number of lanes for each movement).

2) Different signal phasing. 
3) Determining the maximum/minimum traffic volume requirements at which the unconventional left-turn types are inefficient.

4) Determining the minimum length of the U-turn storage lane.

5) Network level impact (i.e. simulate a network with more than one intersection). 


\section{References}

Al-Omari, B., Al-Akhras, K. 2014. Delay Model for U-Turn Movement at Median Openings on Multilane Highways. ITE Journal, 84(3), 42-47.

Bared, J. G., \& Kaisar, E. I. 2002. Median U-turn Design as an Alternative Treatment for Left Turns at Signalized Intersections. ITE Journal-Institute of Transportation Engineering, $72,50-54$

Bared, J., \& Zhang, W. 2007. Synthesis of the Median U-Turn Intersection Treatment, Safety, and Operational Benefits. Federal Highway Administration.

Carter, D., Hummer, J. E., Foyle, R. S., \& Phillips, S. 2005. Operational and Safety Effects of U-Turns at Signalized Intersections. Trasnportation Research Board, 11-18.

Changjiang, Z., Pan, L., Lu, J. J., \& Hongyun, C. 2009. Evaluating the Effects of U-Turns on Level of Service of Signalized Intersections Using Synchro and SimTraffic. Intelligent Vehicles Symposium, IEEE, pp. 971-976.

Dorothy, P., Maleck, T., \& Nolf, S. 1997. Operational Aspects of Michigan Design for Divided Highways. Transportation Research Record, 1579.

Gluck, J., Levinson, H. S., \& Stover, V. 1999. Impacts of Access Management Techniques, NCHRP Report 420. Transportation Research Board.

Highway Capacity Manual. 2000. Washington, D.C: Transportation Research Board, National Research Council.

Hummer, J. E., \& Reid, J. D. 1999. Unconventional Left-Turn Alternatives for Urban and Suburban Arterials_-An Update. Urban Street Symposium.

Kach, B. 1992. The Comparative Accident Experience of Directional and Bi-directional Signalized Intersections. Michigan Department of Transportation.

Levinson, H. S., Koepke, F. J., Geiger, D., Allyn, D., \& Palumbo, C. 2000. Indirect Left Turns - The Michigan Experience. the Fourth National Access Managment Conference. 
Liu, P., Lu, J. J., Pirinccioglu, F., Dissanayake, S., \& Sokolow, G.2007. Should Direct Left-turns from Driveways be Replaced by Right-turns Followed by U-turns? The Safety and Operational Comparison in Florida. the 3rd Urban Street Symposium. Seattle, Washington.

Lu, J. J., Pirinccioglu, F., \& Pernia, J. C. 2004. Safety Evaluation of Right Turns Followed by U-turns at Signalized Intersections (Six or More Lanes) as an Alternative to Direct Left Turns: Conflict Analysis.

Lu, J. J., Pirinccioglu, F., \& Pernia, J. C. 2005. Safety Evaluation of Right Turns Followed by U-turns at Signalized Intersections (4 Lanes) as an Alternative to Direct Left Turns: Conflict Analysis.

Lu, J., Dissanayake, S., \& Castillo, N. 2001. Safety Evaluation of Right Turns Followed by U-turns as an Alternative to Direct Left Turns: Crash Data Analysis.

Lu, J., Dissanayake, S., \& Xu, L. 2001. Safety Evaluation of Right Turns Followed by U-turns as an Alternative to Direct Left Turns: Crash Data Analysis.

Lu, L., Wei, D., Lu, J. J., \& Li, Z. 2012. Analysis of Signalized Intersection U-Turn Design Based on the Micro-Simulation Study. American Society of Civil Engineers, 2266-2277.

Maki, R. E. 1996. Directional Crossovers: Michigan's Preferred Left-Turn Strategy. Annual Meeting of Transportation Research Board.

Potts, I. B., Harwood, D. W., Torbic, D. J., Richard, K. R., Gluck, J. S., \& Levinson, H. S. 2004. Safety of U-turns at Unsignalized Median Opening, NCHRP Report 524. National Cooperative Highway Research Program, Transportation Research Board.

Reid, J. D., \& Hummer, J. E. 1999. Analyzing System Travel Time in Arterial Corridors with Unconventional Designs Using Microscopic Simulation. Transportation Research Record, 1678, 208-215. 
Ronglong, Z., Jingjing, F., \& Liu, P. 2010. Selection of Optimal U-Turn Locations for indirect Left-Turn Treatments on Urban Streets. Journal of Southeast University, 26, 628-632.

Topp, A., \& Hummer, J. E. 2005. Comparison of Two Median U-Turn Design Alternatives Using Microscopic Simulation. 3rd International Symposium on Highway Geometric Design. Chicago, IL.

Xu, L. 2001. Right Turns Followed by U-turns vs. Direct Left Turns: A comparison of Safety Issues. ITE Journal, 71, 36-43.

Yang, X. K., \& Zhou, H. G. 2004. CORSIM-Based Simulation Approach to Evaluation of Direct Left Turn versus Right Turn Plus U-Turn from Driveways. Journal of Transportation Engineering-ASCE, 130, 68-75.

Zhou, H., Lu, J. J., Castillo, N., \& Williams, K. M. 2000. Operational Effects of a Right Turn Plus U-turn Treatment as an Alternative to a Direct Left Turn Movement from a Driveway. Proceedin of the 4th National Conference on Access Managment. Portland, Oregon.

Zhou, H., Lu, J. J., Castillo, N., Yang, X. K., \& Williams, K. M. 2001. Safety and Operational Effects of Replacing a Full Median Opening with a Directional Median Opening. Annual Meeting of Institute of Transportation Engineers. Chiccago.

Zhou, H., Lu, J. J., Yang, X. K., Dissanayake, S., \& Williams, K. M. 2002. Operational Effects of U-Turns as Alternatives to Direct Left Turns from Driveways. Transportation Research Record, TRB, National Research Council, 72-79. 


\section{List of Symbols}

The following symbols are used in this paper:

DLT $=$ Direct left-turn

LOS= Level of Service

RTUT= Right-turn followed by a U-turn at the traffic signal

TWLTLs $=$ Two-way left-turn lanes

UTRT $=$ U-turn followed by a right-turn

$\mathrm{VKT}=$ Vehicle kilometers travelled

$\mathrm{vph}=$ Vehicles per hour 
Tables

Table 1. Comparison of delay (sec), u-turn locations at 200 meters from the intersection

\begin{tabular}{|c|c|c|c|c|c|c|c|c|c|c|}
\hline \multirow{3}{*}{ Case No. } & \multirow{3}{*}{$\begin{array}{l}\text { Traffic } \\
\text { Volume } \\
\text { (vph) }\end{array}$} & \multicolumn{9}{|c|}{ Left Turn \% on Northbound and Southbound } \\
\hline & & \multicolumn{3}{|c|}{ I) $\mathbf{1 5 \%}$} & \multicolumn{3}{|c|}{ II) $30 \%$} & \multicolumn{3}{|c|}{ III) $45 \%$} \\
\hline & & DLT & RTUT & UTRT & DLT & RTUT & UTRT & DLT & RTUT & UTRT \\
\hline \multirow{4}{*}{200.1} & 3,500 & 23.9 & 22.4 & 17.3 & 24.1 & 24.5 & 17.7 & 29.5 & 26.5 & 20.1 \\
\hline & 5,000 & 28.8 & 24.5 & 19.1 & 29.0 & 26.5 & 20.1 & 56.1 & 30.1 & 24.2 \\
\hline & 6,000 & 36.9 & 25.9 & 20.5 & 37.6 & 27.9 & 21.7 & 87.9 & 31.2 & 22.5 \\
\hline & 7,000 & 42.6 & 28.9 & 22.9 & 49.8 & 31.4 & 24.4 & 168.4 & 36.7 & 29.2 \\
\hline \multirow{4}{*}{200.2} & 3,500 & 25.0 & 20.3 & 15.7 & 25.3 & 23.3 & 19.6 & 51.8 & 24.2 & 25.8 \\
\hline & 5,000 & 30.8 & 20.9 & 17.2 & 32.1 & 24.1 & 22.0 & 117.4 & 27.7 & 30.8 \\
\hline & 6,000 & 36.5 & 23.2 & 19.2 & 40.4 & 27.0 & 21.8 & 181.0 & 31.9 & 41.0 \\
\hline & 7,000 & 60.6 & 26.0 & 22.6 & 87.8 & 35.0 & 28.6 & 182.2 & 64.0 & 96.9 \\
\hline \multirow{4}{*}{200.3} & 3,500 & 25.3 & 23.8 & 20.0 & 25.5 & 26.7 & 19.8 & 67.6 & 24.6 & 25.9 \\
\hline & 5,000 & 29.5 & 21.8 & 18.1 & 31.4 & 24.6 & 21.2 & 111.9 & 28.6 & 35.3 \\
\hline & 6,000 & 36.5 & 25.0 & 21.5 & 36.8 & 28.0 & 27.7 & 149.5 & 42.0 & 70.6 \\
\hline & 7,000 & 74.7 & 28.5 & 25.1 & 75.9 & 34.5 & 50.9 & 158.2 & 79.4 & 69.4 \\
\hline \multirow{4}{*}{200.4} & 3,500 & 25.2 & 23.3 & 17.5 & 20.6 & 25.8 & 18.4 & 27.4 & 28.5 & 21.2 \\
\hline & 5,000 & 29.9 & 27.6 & 20.9 & 29.9 & 29.7 & 22.0 & 48.4 & 35.5 & 25.7 \\
\hline & 6,000 & 35.5 & 30.1 & 24.5 & 37.7 & 32.5 & 26.0 & 117.8 & 39.9 & 31.0 \\
\hline & 7,000 & 58.2 & 40.4 & 36.1 & 80.4 & 39.3 & 30.8 & 160.0 & 76.4 & 45.1 \\
\hline \multirow{4}{*}{200.5} & 3,500 & 25.7 & 26.0 & 22.3 & 25.7 & 28.4 & 19.7 & 56.3 & 27.4 & 24.1 \\
\hline & 5,000 & 29.2 & 24.5 & 20.4 & 29.5 & 28.9 & 23.8 & 98.0 & 33.1 & 34.8 \\
\hline & 6,000 & 36.0 & 29.5 & 24.7 & 38.0 & 32.2 & 28.1 & 112.7 & 59.0 & 67.3 \\
\hline & 7,000 & 72.8 & 39.6 & 36.8 & 81.5 & 44.6 & 51.8 & 142.8 & 68.4 & 70.8 \\
\hline
\end{tabular}


Table 2. Comparison of delay (sec), u-turn locations at 100 meters from the intersection

\begin{tabular}{|c|c|c|c|c|c|c|c|c|c|c|}
\hline \multirow{3}{*}{ Case No. } & \multirow{3}{*}{$\begin{array}{l}\text { Traffic } \\
\text { Volume } \\
\text { (vph) }\end{array}$} & \multicolumn{9}{|c|}{ Left Turn \% on Northbound and Southbound } \\
\hline & & \multicolumn{3}{|c|}{ I) $15 \%$} & \multicolumn{3}{|c|}{ II) $30 \%$} & \multicolumn{3}{|c|}{ III) $45 \%$} \\
\hline & & DLT & RTUT & UTRT & DLT & RTUT & UTRT & DLT & RTUT & UTRT \\
\hline \multirow{4}{*}{100.1} & 3,500 & 23.9 & 17.4 & 16.5 & 24.1 & 18.9 & 17.4 & 29.5 & 21.9 & 21.3 \\
\hline & 5,000 & 28.8 & 19.1 & 17.6 & 28.9 & 21.4 & 19.0 & 56.1 & 26.0 & 26.5 \\
\hline & 6,000 & 36.9 & 20.4 & 18.5 & 37.5 & 23.0 & 22.7 & 87.9 & 33.3 & 28.6 \\
\hline & 7,000 & 42.6 & 23.1 & 23.0 & 49.7 & 26.4 & 31.4 & 168.4 & 81.1 & 202.4 \\
\hline \multirow{4}{*}{100.2} & 3,500 & 25.0 & 16.1 & 14.9 & 25.3 & 20.0 & 18.1 & 51.8 & 22.7 & 25.0 \\
\hline & 5,000 & 30.8 & 17.4 & 15.8 & 32.1 & 20.5 & 19.8 & 117.4 & 28.6 & 44.1 \\
\hline & 6,000 & 36.5 & 19.3 & 18.1 & 40.4 & 24.2 & 27.2 & 181.0 & 72.5 & 117.6 \\
\hline & 7,000 & 60.6 & 21.0 & 21.5 & 87.8 & 28.2 & 61.4 & 182.2 & 134.6 & 233.1 \\
\hline \multirow{4}{*}{100.3} & 3,500 & 25.3 & 19.7 & 20.0 & 25.5 & 22.9 & 18.7 & 67.6 & 23.0 & 27.6 \\
\hline & 5,000 & 29.5 & 18.5 & 15.8 & 31.3 & 21.4 & 19.7 & 111.9 & 40.6 & 83.4 \\
\hline & 6,000 & 36.5 & 21.5 & 21.1 & 36.7 & 26.4 & 34.0 & 149.5 & 85.3 & 90.9 \\
\hline & 7,000 & 74.7 & 24.9 & 23.3 & 75.9 & 40.6 & 63.4 & 158.2 & 92.2 & 103.6 \\
\hline \multirow{4}{*}{100.4} & 3,500 & 25.2 & 18.2 & 16.5 & 20.6 & 19.8 & 17.7 & 27.4 & 24.2 & 24.3 \\
\hline & 5,000 & 29.9 & 20.9 & 18.5 & 29.9 & 23.0 & 19.7 & 48.4 & 31.1 & 43.2 \\
\hline & 6,000 & 35.5 & 25.1 & 27.4 & 37.7 & 28.7 & 32.2 & 117.8 & 89.7 & 79.7 \\
\hline & 7,000 & 58.2 & 45.3 & 107.6 & 80.4 & 36.3 & 70.1 & 160.0 & 128.3 & 125.5 \\
\hline \multirow{4}{*}{100.5} & 3,500 & 25.7 & 22.6 & 22.3 & 25.7 & 25.2 & 18.5 & 56.3 & 24.6 & 28.4 \\
\hline & 5,000 & 29.2 & 20.3 & 17.6 & 29.5 & 24.9 & 26.2 & 98.0 & 48.4 & 89.6 \\
\hline & 6,000 & 36.0 & 24.7 & 24.5 & 38.0 & 28.8 & 50.4 & 112.7 & 88.8 & 84.5 \\
\hline & 7,000 & 72.8 & 37.6 & 94.3 & 81.5 & 63.4 & 66.2 & 142.8 & 82.2 & 83.5 \\
\hline
\end{tabular}


Table 3. Comparison of delay (sec), u-turn locations at 50 meters from the intersection

\begin{tabular}{|c|c|c|c|c|c|c|c|c|c|c|}
\hline \multirow{3}{*}{ Case No. } & \multirow{3}{*}{$\begin{array}{l}\text { Traffic } \\
\text { Volume } \\
\text { (vph) }\end{array}$} & \multicolumn{9}{|c|}{ Left Turn \% on Northbound and Southbound } \\
\hline & & \multicolumn{3}{|c|}{ I) $15 \%$} & \multicolumn{3}{|c|}{ II) $30 \%$} & \multicolumn{3}{|c|}{ III) $45 \%$} \\
\hline & & DLT & RTUT & UTRT & DLT & RTUT & UTRT & DLT & RTUT & UTRT \\
\hline \multirow{4}{*}{50.1} & 3,500 & 23.9 & 15.4 & 15.9 & 24.1 & 17.1 & 18.8 & 29.5 & 19.7 & 21.4 \\
\hline & 5,000 & 28.8 & 16.8 & 17.7 & 28.9 & 18.8 & 21.3 & 56.1 & 28.1 & 491.8 \\
\hline & 6,000 & 36.9 & 18.1 & 18.5 & 37.6 & 20.4 & 401.2 & 87.9 & 316.2 & 614.4 \\
\hline & 7,000 & 42.6 & 99.7 & 332.8 & 49.8 & 152 & 549.4 & 168.4 & 585.7 & 842.2 \\
\hline \multirow{4}{*}{50.2} & 3,500 & 24.9 & 13.9 & 14.4 & 25.3 & 18.7 & 19.6 & 51.8 & 21.1 & 29.4 \\
\hline & 5,000 & 30.8 & 15.1 & 15.3 & 32.1 & 18.4 & 94.8 & 117.4 & 338.1 & 799.6 \\
\hline & 6,000 & 36.5 & 16.5 & 17.8 & 40.4 & 183.5 & 715.9 & 181.0 & 311.5 & 741.8 \\
\hline & 7,000 & 60.6 & 18.2 & 267.1 & 87.8 & 338.4 & 627.7 & 182.2 & 378.3 & 885.7 \\
\hline \multirow{4}{*}{50.3} & 3,500 & 25.3 & 18.5 & 19.5 & 25.5 & 23.8 & 21.0 & 67.6 & 29.9 & 100.0 \\
\hline & 5,000 & 29.5 & 15.2 & 15.7 & 31.4 & 24.1 & 346 & 111.9 & 468.1 & 595.8 \\
\hline & 6,000 & 36.5 & 18.7 & 26.9 & 36.8 & 418.9 & 534.3 & 149.5 & 503.2 & 706.8 \\
\hline & 7,000 & 74.7 & 24.1 & 224.8 & 75.9 & 403.4 & 571.0 & 158.2 & 498.4 & 888.9 \\
\hline \multirow{4}{*}{50.4} & 3,500 & 25.2 & 15.5 & 16.1 & 20.6 & 17.5 & 47.5 & 27.4 & 21.5 & 23.9 \\
\hline & 5,000 & 29.9 & 18.2 & 18.6 & 29.9 & 20.5 & 78.9 & 48.4 & 249.9 & 274.5 \\
\hline & 6,000 & 35.5 & 32.5 & 226.6 & 37.7 & 113.2 & 555.9 & 117.8 & 313.7 & 691.4 \\
\hline & 7,000 & 58.2 & 79.9 & 530.3 & 80.4 & 246.7 & 548.1 & 160.0 & 359.1 & 663.9 \\
\hline \multirow{4}{*}{50.5} & 3,500 & 25.7 & 21.4 & 22.2 & 25.7 & 25.6 & 19.5 & 56.3 & 40.5 & 36.9 \\
\hline & 5,000 & 29.2 & 17.0 & 17.4 & 29.5 & 95.2 & 326.3 & 98.0 & 392.8 & 544.9 \\
\hline & 6,000 & 36.0 & 21.9 & 105.6 & 38.0 & 230.1 & 568.4 & 112.7 & 311.6 & 594.3 \\
\hline & 7,000 & 72.8 & 96.3 & 484.9 & 81.5 & 488.8 & 627.7 & 142.8 & 575.8 & 620.7 \\
\hline
\end{tabular}


Table 4. Summary of the LOS for left-turn treatments

\begin{tabular}{|c|c|c|c|c|c|c|}
\hline \multirow{2}{*}{$\begin{array}{l}\text { U-Turn } \\
\text { Locations }\end{array}$} & \multirow{2}{*}{$\begin{array}{l}\text { Left-Turn } \\
(\%)\end{array}$} & \multirow{2}{*}{$\begin{array}{l}\% \text { of Vehicles on } \\
\text { each Approach }\end{array}$} & \multirow{2}{*}{ Traffic volume } & \multicolumn{3}{|c|}{ Left-Turn Control Type } \\
\hline & & & & DLT & RTUT & UTRT \\
\hline \multirow{15}{*}{ 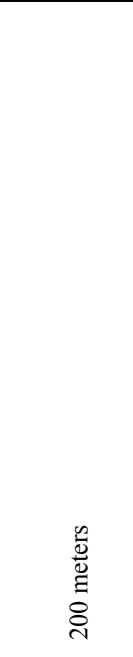 } & \multirow{3}{*}{ Case I $(15 \%)$} & \multirow{3}{*}{ Cases $1,2,3,4,5$} & Low $(3,500-5,000 \mathrm{vph})$ & $\mathrm{C}$ & $\mathrm{C}$ & $\mathrm{B}$ \\
\hline & & & Moderate $(5,000-6,000 \mathrm{vph})$ & $\mathrm{C}$ & $\mathrm{C}$ & $\mathrm{B}$ \\
\hline & & & High $(6,000-7,000 \mathrm{vph})$ & $\mathrm{D}$ & $\mathrm{C}$ & $\mathrm{C}$ \\
\hline & \multirow{3}{*}{$\begin{array}{l}\text { Case II } \\
(30 \%)\end{array}$} & \multirow{3}{*}{ Cases $1,2,3,4,5$} & Low $(3,500-5,000 \mathrm{vph})$ & $\bar{C}$ & $\mathrm{C}$ & $\mathrm{C}$ \\
\hline & & & Moderate $(5,000-6,000 \mathrm{vph})$ & $\overline{\mathrm{C}}$ & $\overline{\mathrm{C}}$ & $\overline{\mathrm{C}}$ \\
\hline & & & High $(6,000-7,000 \mathrm{vph})$ & $\mathrm{E}$ & $\mathrm{C}$ & $\mathrm{C}$ \\
\hline & \multirow{9}{*}{$\begin{array}{l}\text { Case III } \\
(45 \%)\end{array}$} & \multirow{3}{*}{ Case 1} & Low $(3,500-5,000 \mathrm{vph})$ & $\mathrm{D}$ & $\mathrm{C}$ & $\mathrm{C}$ \\
\hline & & & Moderate $(5,000-6,000 \mathrm{vph})$ & $\mathrm{E}$ & $\mathrm{C}$ & $\mathrm{C}$ \\
\hline & & & High $(6,000-7,000 \mathrm{vph})$ & $\mathrm{F}$ & $\mathrm{C}$ & $\mathrm{C}$ \\
\hline & & \multirow{3}{*}{ Cases 2,3 } & Low $(3,500-5,000 \mathrm{vph})$ & $\mathrm{F}$ & $\mathrm{C}$ & $\mathrm{C}$ \\
\hline & & & Moderate $(5,000-6,000 \mathrm{vph})$ & $\mathrm{F}$ & $\mathrm{D}$ & $\mathrm{D}$ \\
\hline & & & High $(6,000-7,000$ vph) & $\overline{\mathrm{F}}$ & E & E \\
\hline & & \multirow{3}{*}{ Cases 4,5} & Low $(3,500-5,000 \mathrm{vph})$ & $\mathrm{D}$ & $\mathrm{C}$ & $\mathrm{C}$ \\
\hline & & & Moderate $(5,000-6,000 \mathrm{vph})$ & $\overline{\mathrm{F}}$ & $\mathrm{D}$ & $\mathrm{D}$ \\
\hline & & & High $(6,000-7,000 \mathrm{vph})$ & $\overline{\mathrm{F}}$ & $\mathrm{E}$ & $\mathrm{E}$ \\
\hline \multirow{15}{*}{ 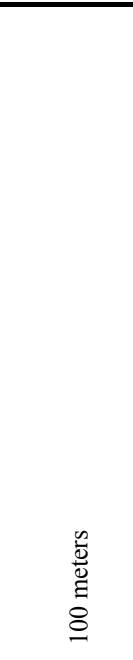 } & \multirow{6}{*}{ Case I $(15 \%)$} & \multirow{3}{*}{ Cases $1,2,3$} & Low $(3,500-5,000 \mathrm{vph})$ & $\mathrm{C}$ & $\mathrm{B}$ & B \\
\hline & & & Moderate $(5,000-6,000 \mathrm{vph})$ & $\mathrm{C}$ & B & B \\
\hline & & & High $(6,000-7,000 \mathrm{vph})$ & $\mathrm{D}$ & $\mathrm{C}$ & $\mathrm{C}$ \\
\hline & & \multirow{3}{*}{ Cases 4,5} & Low $(3,500-5,000 \mathrm{vph})$ & $\mathrm{C}$ & $\mathrm{B}$ & $\mathrm{B}$ \\
\hline & & & Moderate $(5,000-6,000 \mathrm{vph})$ & $\mathrm{C}$ & $\mathrm{C}$ & $\mathrm{C}$ \\
\hline & & & High $(6,000-7,000 \mathrm{vph})$ & $\mathrm{D}$ & $\mathrm{D}$ & $\mathrm{E}$ \\
\hline & \multirow{3}{*}{$\begin{array}{l}\text { Case II } \\
(30 \%)\end{array}$} & \multirow{3}{*}{ Cases $1,2,3,4,5$} & Low $(3,500-5,000 \mathrm{vph})$ & $\mathrm{C}$ & $\mathrm{C}$ & $\mathrm{D}$ \\
\hline & & & Moderate $(5,000-6,000 \mathrm{vph})$ & $\mathrm{C}$ & $\mathrm{C}$ & $\mathrm{C}$ \\
\hline & & & High $(6,000-7,000 \mathrm{vph})$ & $\mathrm{E}$ & $\mathrm{C}$ & $\mathrm{D}$ \\
\hline & \multirow{6}{*}{$\begin{array}{l}\text { Case III } \\
(45 \%)\end{array}$} & \multirow{3}{*}{ Case 1} & Low $(3,500-5,000 \mathrm{vph})$ & $\mathrm{D}$ & $\mathrm{C}$ & $\mathrm{C}$ \\
\hline & & & Moderate $(5,000-6,000 \mathrm{vph})$ & $\mathrm{E}$ & $\mathrm{C}$ & $\mathrm{C}$ \\
\hline & & & High $(6,000-7,000 \mathrm{vph})$ & $\overline{\bar{F}}$ & $\mathrm{E}$ & $\bar{F}$ \\
\hline & & & Low $(3,500-5,000 \mathrm{vph})$ & $E$ & $\mathrm{C}$ & $\mathrm{D}$ \\
\hline & & Cases 2,3,4,5 & Moderate $(5,000-6,000 \mathrm{vph})$ & $\mathrm{F}$ & $\mathrm{E}$ & $\mathrm{F}$ \\
\hline & & & High $(6,000-7,000 \mathrm{vph})$ & $\mathrm{F}$ & $\mathrm{F}$ & $\mathrm{F}$ \\
\hline & & & Low $(3,500-5,000 \mathrm{vph})$ & $\overline{\mathrm{C}}$ & $\mathrm{B}$ & $\mathrm{B}$ \\
\hline & & Cases $1,2,3$ & Moderate $(5,000-6,000 \mathrm{vph})$ & $\mathrm{C}$ & $\mathrm{B}$ & B \\
\hline & $C=-1=0$ & & High $(6,000-7,000 \mathrm{vph})$ & $\mathrm{D}$ & $\mathrm{D}$ & $\mathrm{F}$ \\
\hline & Casc $1(15 / 0)$ & & Low $(3,500-5,000 \mathrm{vph})$ & $\mathrm{C}$ & $\mathrm{B}$ & $\mathrm{B}$ \\
\hline & & Cases 4,5 & Moderate $(5,000-6,000 \mathrm{vph})$ & $\mathrm{C}$ & $\mathrm{C}$ & $\mathrm{E}$ \\
\hline & & & High $(6,000-7,000 \mathrm{vph})$ & $\mathrm{D}$ & $\mathrm{E}$ & $\mathrm{F}$ \\
\hline & & & Low $(3,500-5,000 \mathrm{vph})$ & $\mathrm{C}$ & $\mathrm{B}$ & B \\
\hline & & Case 1 & Moderate $(5,000-6,000 \mathrm{vph})$ & $\mathrm{C}$ & $\mathrm{B}$ & $\mathrm{F}$ \\
\hline & Case II & & High $(6,000-7,000 \mathrm{vph})$ & $\mathrm{D}$ & $\bar{F}$ & F \\
\hline & $(30 \%)$ & & Low $(3,500-5,000 \mathrm{vph})$ & $\mathrm{C}$ & $\mathrm{C}$ & $F$ \\
\hline & & Cases 2,3,4,5 & Moderate $(5,000-6,000 \mathrm{vph})$ & $\mathrm{C}$ & $\mathrm{F}$ & $\mathrm{F}$ \\
\hline & & & High $(6,000-7,000 \mathrm{vph})$ & $\mathrm{E}$ & $\mathrm{F}$ & $\mathrm{F}$ \\
\hline$\frac{n}{2}$ & & & Low $(3,500-5,000 \mathrm{vph})$ & $E$ & $\mathrm{~F}$ & $\mathrm{~F}$ \\
\hline 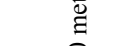 & $\begin{array}{l}\text { Case III } \\
(45 \%)\end{array}$ & Cases $1,2,3,4,5$ & Moderate $(5,000-6,000 \mathrm{vph})$ & $\mathrm{F}$ & $\mathrm{F}$ & $\mathrm{F}$ \\
\hline in & & & High $(6,000-7,000 \mathrm{vph})$ & F & F & F \\
\hline
\end{tabular}




\section{List of Figure Captions}

Figure 1: Indirect left-turn control types

Figure 2: Phasing diagrams for the three left-turn treatments

Figure 3: Phasing diagrams for unconventional left-turn treatments

Figure 4: Experimental design

Figure 5: Delay comparison for case 200.I.1

Figure 6: VKT comparison for case 200.I.1

Figure 7: Impact of U-turn locations 


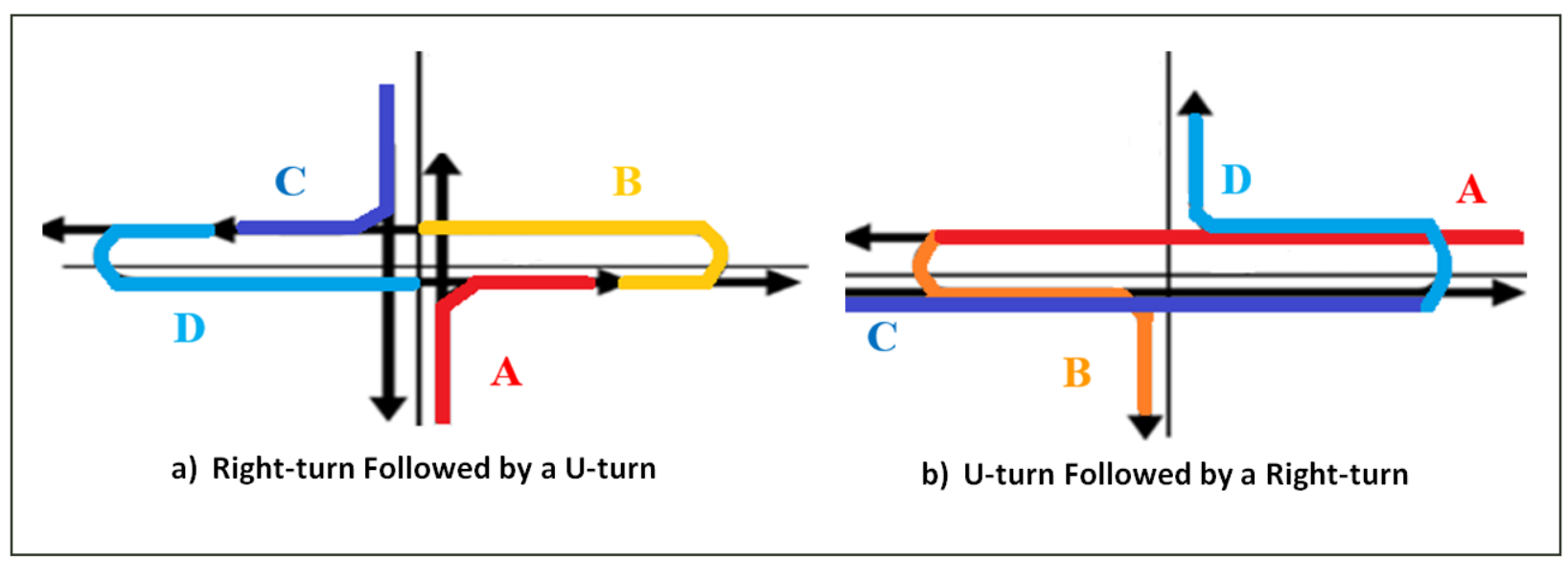




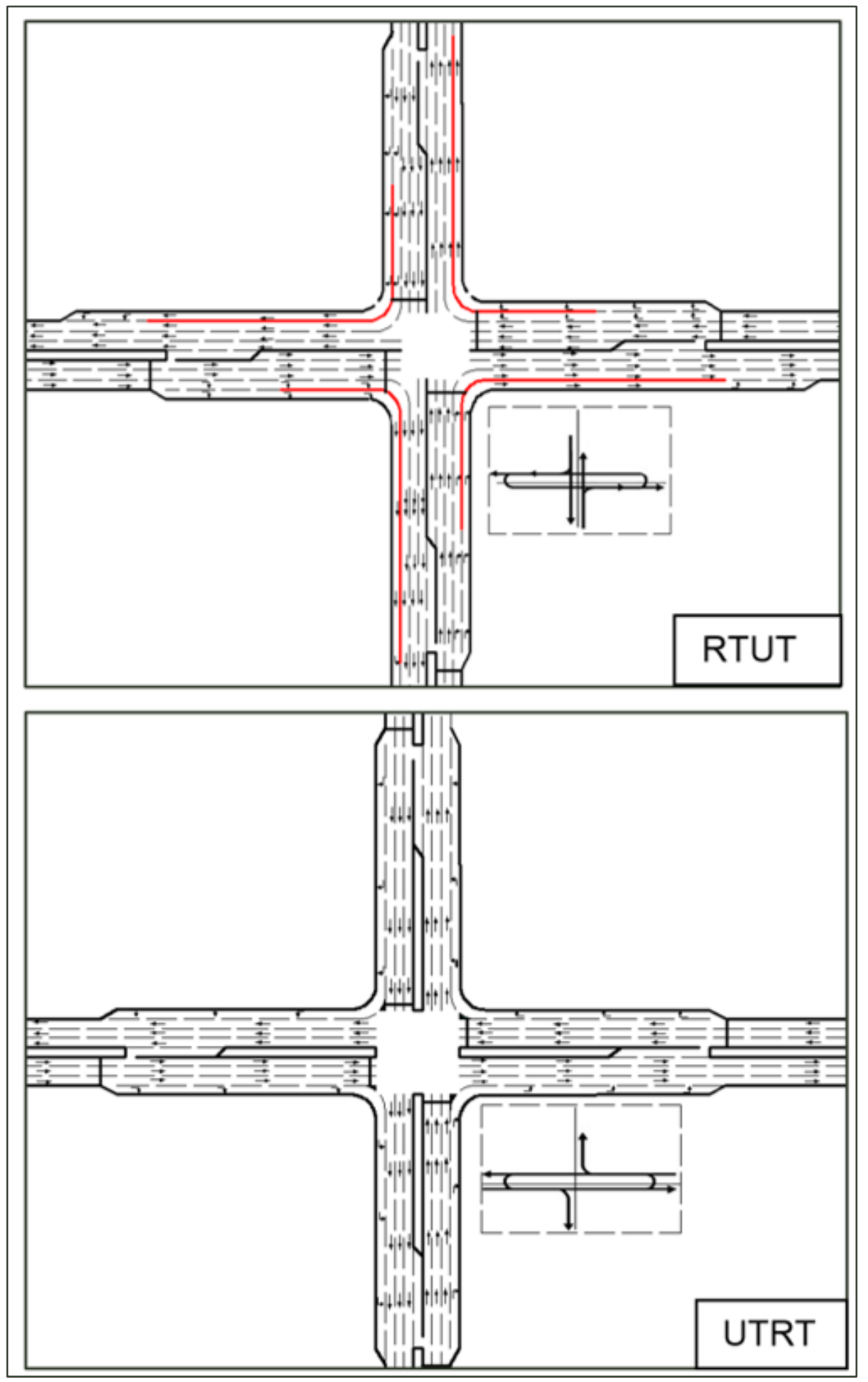




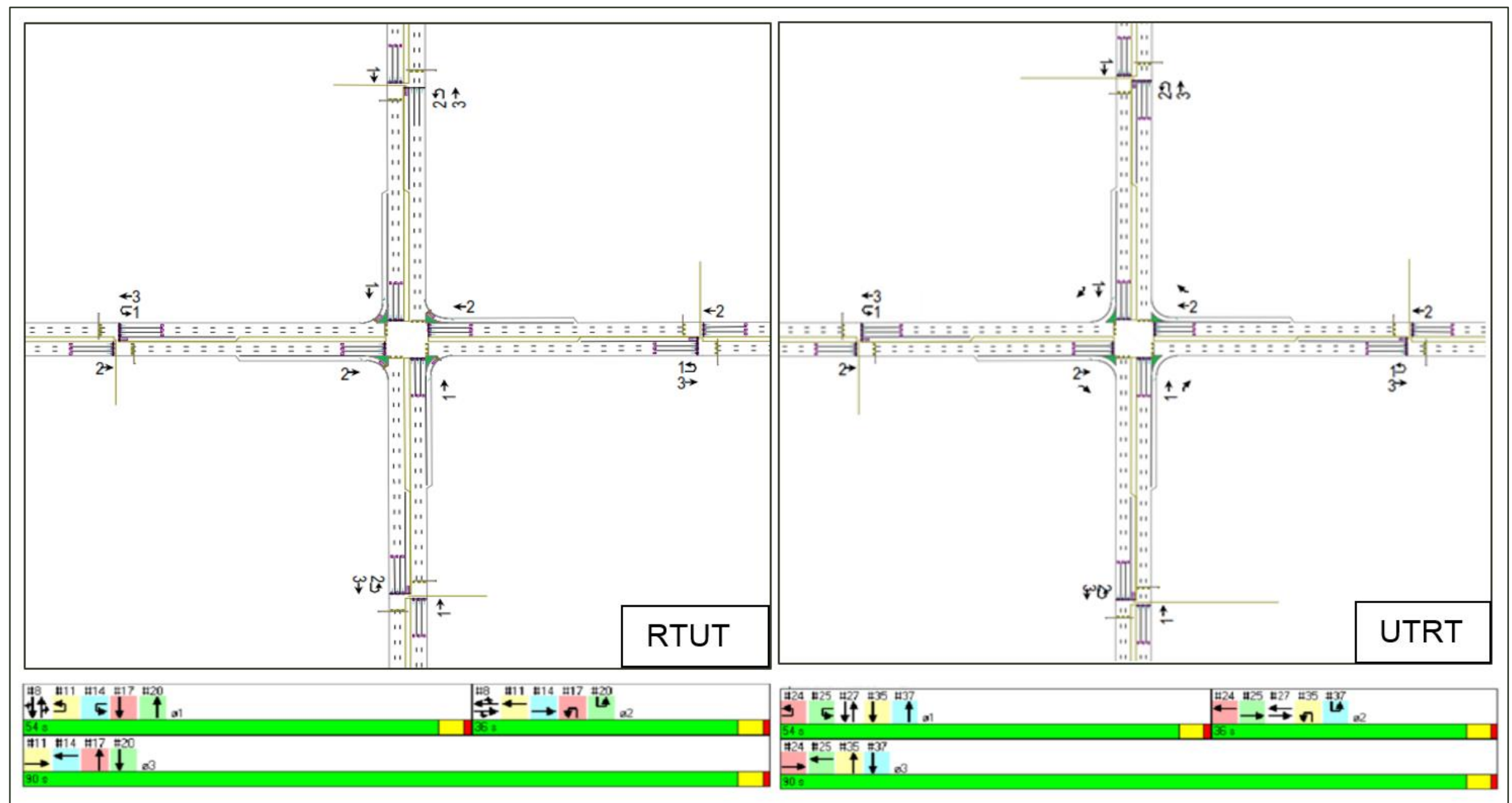




Traffic Volume (vph)
\begin{tabular}{|l|l|l|l|l|l|}
\hline 3,500 & 5,000 & & 6,000 & & 7,000 \\
\cline { 3 - 3 } & & & &
\end{tabular}

Left-turn Control Type

Left-turn Control Type
\begin{tabular}{|l|l|l|l|}
\hline a) DLT & b) RTUT & & c) UTRT \\
\hline
\end{tabular}

$\%$ of Vheicles on each Approach

\begin{tabular}{|c|c|c|c|c|}
\hline $\mathbf{1}$ & $\mathbf{2}$ & $\mathbf{3}$ & $\mathbf{4}$ & $\mathbf{5}$ \\
\hline NB: $25 \%$ & NB: $35 \%$ & NB: $45 \%$ & NB: $35 \%$ & NB: $45 \%$ \\
\hline EB: $25 \%$ & EB: $15 \%$ & EB: $15 \%$ & EB: $35 \%$ & EB: $25 \%$ \\
\hline SB: $25 \%$ & SB: $35 \%$ & SB: $35 \%$ & SB: $15 \%$ & SB: $15 \%$ \\
\hline WB: $25 \%$ & WB: $15 \%$ & WB: $15 \%$ & WB: $15 \%$ & WB: $15 \%$ \\
\hline
\end{tabular}

$\%$ of Vheicles for each Turning Movement

\begin{tabular}{|c|c|c|c|c|c|c|c|c|c|c|c|}
\hline \multicolumn{4}{|c|}{$\bar{I}$} & \multicolumn{4}{|c|}{ II } & \multicolumn{4}{|c|}{ III } \\
\hline & Right-turn & Through & Left-turn & & Right-turn & Through & Left-turn & & Right-turn & Through & Left-turn \\
\hline NB & $10 \%$ & $75 \%$ & $15 \%$ & NB & $10 \% 6$ & $75 \%$ & $15 \%$ & NB & $10 \%$ & $75 \%$ & $15 \%$ \\
\hline $\mathrm{EB}$ & $10 \%$ & $65 \%$ & $25 \%$ & $\mathrm{~EB}$ & $10 \%$ & $65 \%$ & $25 \%$ & EB & $10 \%$ & $65 \%$ & $25 \%$ \\
\hline SB & $10 \%$ & $75 \%$ & $15 \%$ & SB & $10 \%$ & $75 \%$ & $15 \%$ & SB & $10 \%$ & $75 \%$ & $15 \%$ \\
\hline WB & $10 \%$ & $65 \%$ & $25 \%$ & WB & $10 \%$ & $65 \%$ & $25 \%$ & WB & $10 \%$ & $65 \%$ & $25 \%$ \\
\hline
\end{tabular}

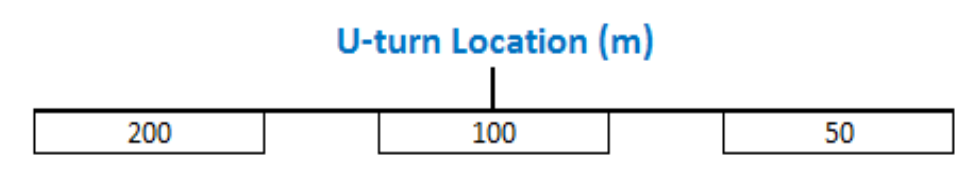




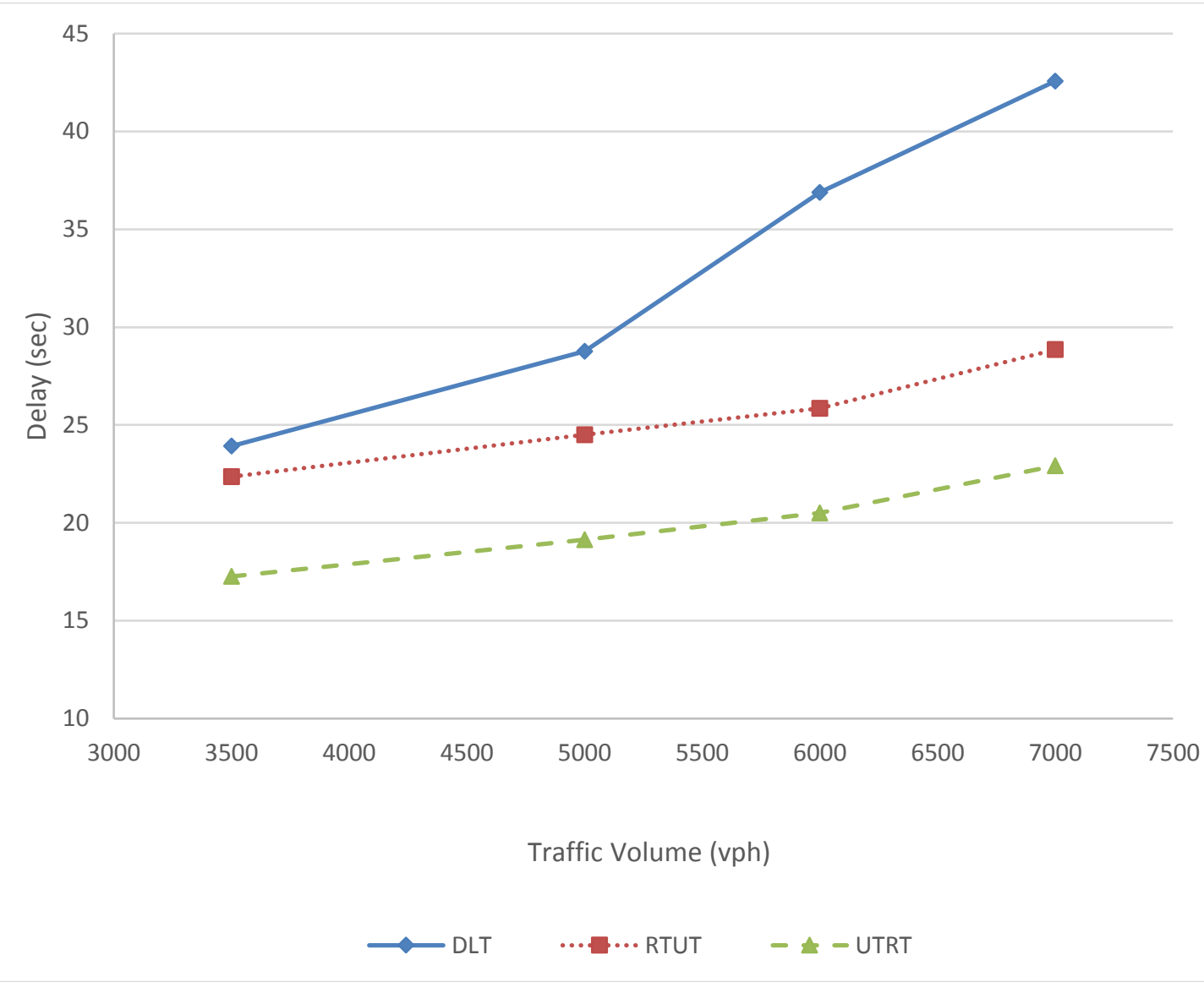




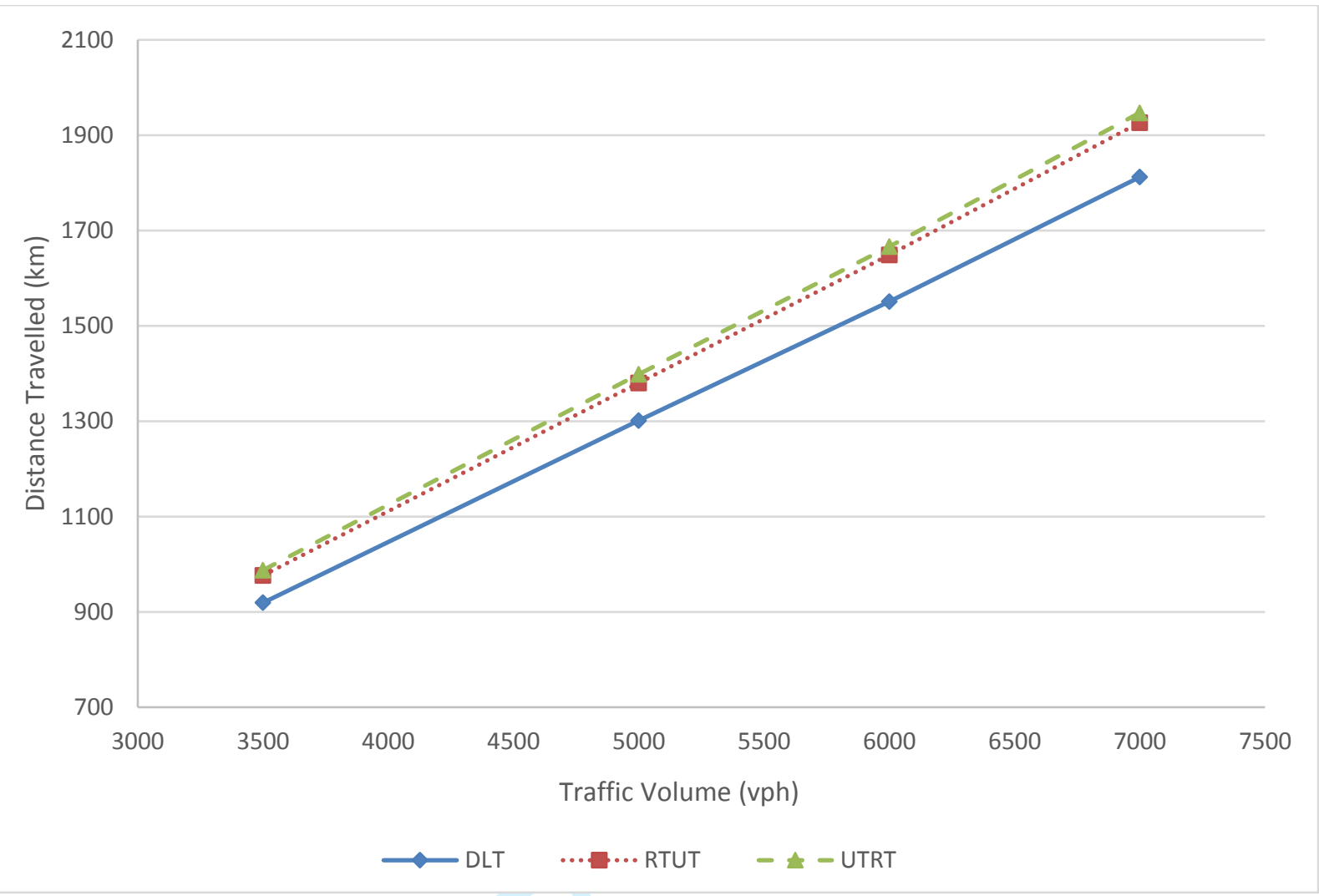




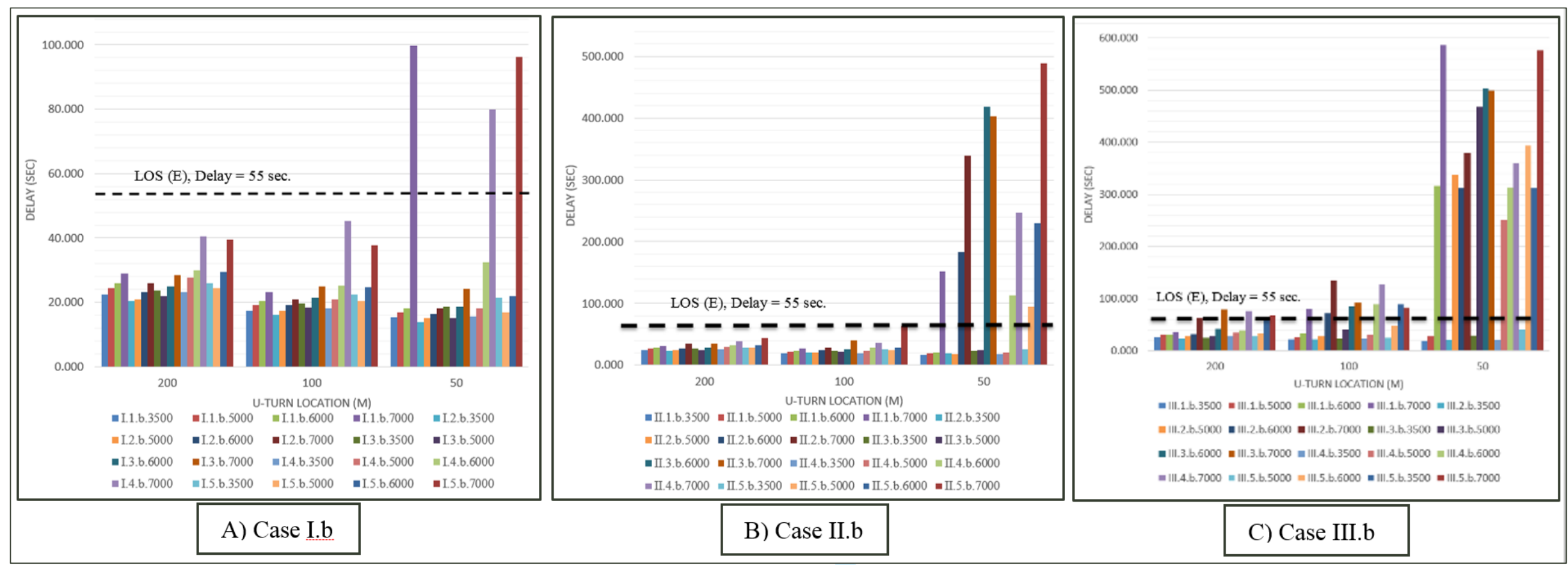

